\title{
A criação de estratégia de comunicação para prevenção em saúde através do design centrado no ser humano
}

\author{
Building communication strategy on health \\ prevention through the human-centered design
}

design centrado no ser humano, estratégias de comunicação, prevenção
Há uma necessidade latente por desenvolver estratégias de comunicação sobre prevenção de doenças de modo eficiente e identificamos o design como um potencial agente para criar materiais de comunicação que sejam capazes de promover o autocuidado. A fim de analisar um processo de design para desenvolver este tipo de artefato, foi realizada uma pesquisa-ação no Centro de Saúde IAPI em Porto Alegre. O objetivo da ação foi propor uma estratégia para promover o autocuidado em relação ao câncer de colo de útero. O processo foi efetuado a partir da perspectiva do design centrado no ser humano - HCD, que busca criar soluções desejáveis pelas pessoas e viáveis para as organizações, a partir de três fases: a) ouvir, na qual se coleta histórias e inspirações das pessoas; b) criar, que visa traduzir em protótipos, os conhecimentos coletados; e, c) disseminar, onde os protótipos são aperfeiçoados e testados junto aos usuários. Para estratégias de comunicação, apoiou-se nos estudos de design sobre retórica visual-verbal. Como resultados, essa abordagem de design mostrouse adequada para criar estratégias de comunicação voltadas a comportamentos de autocuidado, que objetivam empoderar usuários a mudar seu comportamento.

human-centered design, communication strategies, prevention
It has been identified a latent need for developing efficient communication strategies for prevention of diseases and also, design as a potential agent to create communications artifacts that are able to promote self-care. In order to analyze a design process that develops this kind of artifact, an action research in IAPI Health Center in Porto Alegre was done. The action's goal was to design a strategy to promote self-care to prevent cervical cancer. The process was conducted from the human centered design approach $H C D$, which seeks to create solutions desirable for people and feasible for organizations from three main phases: a) Hear, in which inspirations are originated from stories collected from people; $b$ ) Create, which aims to translate these knowledge into prototypes; and , c) Deliver, where the prototypes are tested and developed with users. Communication strategies were supported by design studies about visual-verbal rhetoric. As results, this design approach has shown adequate to create communication strategies targeted at self-care behaviors, aiming to empower users to change their behavior. 


\section{Introdução}

Diariamente, uma infinidade de informações são recebidas por meio de múltiplos canais: dos tradicionais suportes impressos aos suportes digitais. No âmbito da comunicação visual, há o interesse em compreender como é possível afetar as pessoas no recebimento dessas mensagens. Neste sentido, autores como Frascara (1997) e Bonsiepe (2011) ensinam que é preciso criar mensagens discrimináveis, atrativas, compreensíveis e convincentes para que se destaquem nesse emaranhado de informações. Mensagens que não apenas chamem a atenção do público, mas que os empodere. Frascara (1997) explica que essas devem ser construídas a partir de conhecimentos da percepção visual, psicologia da aprendizagem e do sistema de valores culturais do público a que se dirigem. Bonsiepe (2011:21) clama por uma atitude humanista no exercício das capacidades projetuais para "interpretar a necessidade de grupos sociais e elaborar propostas viáveis, emancipatórias, em forma de artefatos instrumentais e artefatos semióticos". O autor expõe o design como uma atividade ligada a estratégia das aparências, apresentando o mundo da liberdade e do jogo, capaz de provocar predisposições positivas nas pessoas afetadas pelos artefatos, gerando autonomia. Para tal, o autor aponta as virtudes da prática projetual: leveza, intelectualidade, setor público, alteridade e visualidade. Leveza diz respeito a atenção aos fluxos de materiais e energia, a graça, elegância a humor dos artefatos; intelectualidade diz respeito à postura crítica na cultura projetual, problematizar e refletir sobre o seu papel na sociedade; o setor público diz respeito ao cuidado e preocupação com a esfera pública; alteridade concerne à disposição para respeitar outras culturas projetuais com seus valores inerentes; e visualidade, ligada à imagem e à palavra, ao design de informação e seu enfoque para solucionar problemas.

Considerando essas premissas, dentre os diversos propósitos ligados às mensagens, nos ocupamos em estudar aquelas ligadas à mudança de comportamento dos cidadãos, mais especificamente, ligadas aos problemas sociais. Nosso foco de estudo é o âmbito da saúde e temos por objetivo compreender como projetar estratégias de comunicação capazes de gerar a mudança de comportamento necessária aos cidadãos usuários do Sistema Único de Saúde (SUS). Reconhecemos que uma mudança na direção do comportamento preventivo é necessária, uma vez que os custos associados ao tratamento das doenças são elevados, sejam eles financeiros (para o sistema), sejam físicos, sociais ou psicológicos (para os pacientes e familiares). A partir da escolha desse objeto, pôde-se explorar todas as virtudes do design para elaboração de propostas emancipatórias.

Destarte, essa pesquisa usou a estratégia de pesquisa-ação, de natureza exploratória e qualitativa, em que um grupo de pesquisadores da área do design, trabalhou com um grupo de pesquisadores da área de psicologia e profissionais de um centro de atendimento especializado do SUS, que tinham o conhecimento sobre 
aprendizagem e comportamentos desejados dos usuários de saúde. O grupo estava desenvolvendo uma pesquisa para elaborar um material educativo para a prevenção do câncer de colo de útero em usuárias do SUS. Na pesquisa, consideramos este grupo como membros da situação problema, que definiu o objetivo da ação, qual seja, elaborar uma cartilha para as usuárias do SUS (Thiollent, 1996). Entendemos que mais do que uma cartilha, era necessário elaborar uma estratégia para que a informação chegasse as usuárias do SUS e que a partir dela, promoveríamos uma mudança de comportamento das usuárias do SUS. A partir disso, nosso objetivo de pesquisa foi redefinido para compreender como projetar estratégias de comunicação capazes de atingir as usuárias do SUS na busca de um comportamento preventivo em relação ao câncer de colo de útero. Escolhemos o método de design centrado no ser humano para elaborar as estratégias de comunicação que ao mesmo tempo considerasse os sistemas culturais de valores da comunidade e o conhecimento de percepção visual e psicologia da aprendizagem, de forma que as relações estabelecidas com a comunidade sejam compreensíveis, convergentes a conscientização sobre comportamento preventivo.

Durante os meses de outubro de 2013 e dezembro de 2014 nos reunimos com o grupo de pesquisadoras para nos apropriarmos dos conteúdos e estratégias de aprendizagem que deveriam ser usadas no material, bem como discutirmos o avanço do projeto. Nas primeiras reuniões, nos foram passados os resultados das pesquisas desenvolvidas pelo grupo para a proposição do conteúdo do material educativo. $\mathrm{Na}$ análise dos documentos, identificou-se que era central para a construção de um material educativo que promovesse o autocuidado trabalhar com a percepção dos riscos que as mulheres correm se não adotarem medidas adequadas de prevenção. A educação para o autocuidado pressupõe que qualquer ser humano em lucidez, tem condições de decidir, com liberdade e autonomia, o que deve fazer com o seu corpo, de acordo com os seus interesses, visando o seu bem-estar e do coletivo. Estudos demonstravam as dificuldades do autocuidado das usuárias do SUS ligadas ao desconhecimento, e ao constrangimento de expor sua intimidade, e ainda, a ineficácia das abordagens de comunicação dos profissionais da saúde e das campanhas governamentais (Castro et. al, 2011). As pesquisadoras indicaram que o material educativo deveria abordar os seguintes aspectos: identidade (sintomas físicos das doenças sexualmente transmissíveis e representações do Vírus Papiloma Humano), fatores de risco, consequências psicossociais, perspectivas de futuro, percepção de risco e representações emocionais da doença. A partir disso foram realizadas observações diretas no centro de saúde e no entorno, entrevistas com pacientes e com profissionais de saúde para compreender os valores socioculturais do público a que o material se destina. A cada etapa de decisão projetual, nos reunimos com o grupo da psicologia para discutirmos os resultados e estabelecer os próximos passos. 


\section{Estratégias de comunicação e design centrado no ser humano}

O design é uma disciplina projetual que trabalha diretamente com comunicação, no momento que ele materializa determinadas mensagens através de signos, textos, produtos, ele apodera-se destas mensagens para torná-las mais claras aos receptores. Bonsiepe (2011) afirma que o designer realiza a mediação entre a fonte da mensagem e o receptor, produzindo distinções visuais e semânticas da cultura cotidiana de maneira a influenciar emoções, comportamentos e atitudes dos receptores.

Mais do que transmitir mensagens, o design direciona as mensagens de forma que o receptor engaje-se com elas e as compreenda (Frascara, 2006a). Para tanto, mostra-se necessário que a mensagem seja comunicada de forma atraente e criativa. Nesse sentido, Bonsiepe (2011) trabalha com a retórica visual-verbal, um conjunto de estratégias para influenciar comportamentos e emoções dos receptores da mensagem. As técnicas de retórica exploradas pelo autor são: (1) analogia, uma comparação através de sinais semânticos equivalentes; (2) metáfora, em que o significado visual é ilustrado visualmente; (3) inversão metafórica, que faz uso da tensão entre o significado primário e o secundário de maneira que os significantes visuais ilustram o significado primário; (4) metonímia, quando um significado verbal é relacionado com outro por meio de uma conexão temática; (5) sinedoque, quando uma parte representa o todo; (6) especificação, o significante visual é acompanhado por um mínimo texto para dar-lhe uma maior precisão semântica; (7) fusão, quando um sinal visual é integrado a um sistema de sinais em forma de supersinal; (8) paralelismo, em que os significantes verbais e visuais se referem ao mesmo significado; (9) transferência associativa, na qual extrai-se um sinal de uma série de sinais verbais para ilustrar uma imagem, o significado de um significante verbal é visualizado oferecendo para o outro elemento associar-se com esse significado; (10) substituição mimética, em que um sinal visual inserido em uma configuração sintática ocupa mimeticamente parte do espaço visual que corresponderia ao sinal visual dominante; (11) subestima, uma concessão verbal ilustrada com um significante visual; (11) exagero, no qual um significado é visualizado de maneira que exceda o padrão normal; (12) tipograma, significado das letras tipográficas visualizado por intermédio das próprias letras; (13) cadeia, em que um significado representado visualmente é continuado e completado por significantes visuais; (14) comparação, na qual uma comparação iniciada com sinais visuais é continuada com sinais verbais; e (15) metaplasmo, o qual utiliza um pattern de substituição usando a similitude fonética entre componentes semanticamente diferentes (Bonsiepe, 2011:118).

Além de explorar técnicas para fortalecer o poder de uma mensagem, é preciso certificar-se se o artefato criado seja desejável e compreensível aos receptores, para isso, mostra-se necessário conhecer a cultura dos receptores. Nesse sentido, tem-se a abordagem 
de design centrado no ser humano, que incorpora métodos da antropologia e do design participativo para ouvir as pessoas que serão afetadas pelo projeto, preocupando-se com a maneira que elas vêem, interpretam e convivem com os artefatos criados, sejam estes serviços, produtos ou interfaces (Steen, 2008; Sbordone, 2008). Essa abordagem considera que os artefatos projetados serão experimentados de diferentes maneiras pelos usuários, pois os significados destes são atribuídos pelos próprios usuários conforme suas concepções de mundo, cultura, habitus, formas como interagem com tecnologias. No âmbito de sistemas interativos, o processo de design guiado por essa abordagem, segue os princípios estabelecidos pela ISO 9241-210: (1) o design é baseado numa compreensão explicita dos usuários, das tarefas que desenvolvem e dos ambientes em que estão inseridos; (2) usuários são envolvidos em todo o processo de design e desenvolvimento; (3) o design é dirigido e refinado pela avaliação dos usuários (4) o processo é iterativo; (5) o design é endereçado a toda a experiência do usuário; (6) a equipe de design inclui perspectivas e habilidades multidisciplinares (ISO, 2010).

Existem diferentes perspectivas relacionadas ao design centrado no ser humano, visto que é uma metodologia ainda em desenvolvimento. Considerando o uso dessa abordagem em projetos voltados a inovação social, escolhemos a abordagem da IDEO.org por ter sido disseminada mundialmente em uma plataforma aberta (já foram realizados mais de 150.000 downloads) que permite também o compartilhamento de experiências entre os usuários da plataforma (IDEO, 2015). A IDEO (2009) estabelece o processo do HCD, dividido em três fases: o primeiro, Ouvir: na qual se coleta histórias e inspirações das pessoas; o segundo, Criar: visa traduzir em protótipos, os conhecimentos coletados das histórias e inspirações; e o terceiro, Disseminar: onde os protótipos são testados junto aos usuários para avaliar a pertinência destas possíveis soluções. É importante que as soluções estratégicas criadas sejam praticáveis, desejáveis e viáveis (IDEO, 2009).

Na primeira etapa, Ouvir, trabalha-se para estabelecer empatia com àqueles que serão afetados pelo projeto. Para isso é preciso selecionar adequadamente as pessoas e os locais de observação para que boas histórias sejam coletadas. São usadas técnicas de pesquisa qualitativa, como, entrevistas individuais, em grupo, observação dos contextos de uso e busca de inspiração em novos contextos. Estes métodos são de origem antropológica, que o designer explora para investigar e posteriormente traduzir em especificações para possíveis melhorias do artefato que será criado. Estas técnicas visam ainda perceber como é a compreensão das pessoas em relação as experiências.

A segunda etapa, Criar, inicia pela interpretação dos dados e histórias coletadas. É necessário que os dados sejam sintetizados, para ficarem mais organizados e compreensível; para isso, são utilizadas ferramentas, como, personas, mapas de afinidade, entre outros. Com as informações sintetizadas a equipe de projetistas iniciam a parte de ideação, que compreende a geração de insights de projeto, que são 
indicativos de possíveis caminhos que os projetistas podem seguir para responder ao desafio estratégico. Aqueles insights considerados mais pertinentes pela equipe são esboçados, desenvolvidos e prototipados rapidamente, como uma maneira de criar estímulos para os diálogos, gerando aprendizados, sem apegar-se a eles.

A terceira e última etapa, Disseminar, consiste em avaliar se as ideias prototipadas são úteis, desejáveis, viáveis e possíveis de ser implementadas. Assim, os protótipos são aperfeiçoados para a realização de testes junto a comunidade, de maneira que estejam mais próximos do produto ou serviço planejado. Após testado e certificado a pertinência do projeto, são gerados modelos de negócios que identifique as capacidades (humanas, financeiras, de produção e tecnológicas), os parceiros e os canais necessários para viabilizar a solução. Por fim, são criados indicadores para avaliar o resultado alcançado, para a partir disso, evoluir a proposta e de fato implementar.

\section{O processo projetual na Unidade de Saúde da Mulher do Centro de Saúde do IAPI}

No ano 2011, o Governo Federal lançou o Programa Nacional de Controle do Câncer do Colo de Útero, propondo aumentar o orçamento em saúde, para realização de ações preventivas sistêmicas como por exemplo, formas de comunicação que instruam a população sobre como prevenir, diagnosticar e tratar o CCU. A partir do apoio deste Governo Federal, foram realizadas pesquisas na Unidade de Saúde da mulher do Centro de Saúde IAPI de Porto Alegre (Castro, Carlotto, Pizzinato et al., 2011). Como parte das ações da pesquisa, está a criação de estratégias para comunicar às mulheres medidas de prevenção à doença, seus sintomas, tratamento e sobre o Papanicolau, o exame preventivo do Câncer de Colo de Útero, que deve ser feito por todas as mulheres, em especial, mulheres entre 25 e 59 anos, uma vez ao ano (Castro, Carlotto, Pizzinato et al., 2011). A partir da compreensão das informações que deveriam ser comunicadas, iniciou-se o processo HCD, descrito a seguir.

\section{Descrição do processo}

\section{Fase 1 - Ouvir}

A etapa Ouvir ocorreu entre os meses de fevereiro e setembro de 2014. No primeiro momento, observamos as pacientes em situações análogas com o objetivo de identificar seu perfil, seus habitus, comportamentos e interações com diferentes suportes de comunicação. Por meio de registros fotográficos, mapeamos o conjunto de informações as quais elas são expostas ao longo do dia, como em ônibus, parques, ruas e no próprio centro de Saúde IAPI. Os materiais coletados foram analisados a partir das virtudes apontadas por Bonsiepe (2011) para um design mais humanista, com leveza, intelectualidade, setor público, alteridade 
e visualidade; e em relação as técnicas de retórica. Em relação à leveza, alguns deles, como o cartaz do centro da Figura 1, possuem excesso de textos, que dificultam a legibilidade, sem elegância. Os cartazes "aqui tem farmácia popular", à esquerda e o "teste do pezinho", à direita, demonstram maior leveza, destacam de alguma forma as informações mais relevantes e hierarquização dos demais conteúdos. Sobre a intelectualidade, a maior parte deles não possuíam caráter crítico à cultura projetual, de reflexão ao seu papel na sociedade. No quesito de preocupação com esfera pública, como eram ligados à saúde pública, todos atendiam a intenção. Sobre a visualidade, as imagens presentes, em alguns casos, não possuíam relação direta com o que se estava escrito, ou com pouco destaque, como do cartaz do centro, que na parte inferior mostra o símbolo de prevenção do HIV. Considerando as técnicas de retórica, para fixação de significados, encontramos analogias, como no cartaz "aqui tem farmácia popular", onde o centro da bandeira faz uma analogia à uma pílula de remédio e uma fusão de dois significados; no cartaz da direita, foras exploradas as técnicas de metonímia e especificação, utilizou-se ilustrações de pés infantilizados e tipografias gestuais, para demonstrar que se trata um cartaz para cuidados infantis. Na Figura 1, estão os registros do mural da unidade de saúde da mulher do centro de saúde do IAPI (à direita e centro), e, à esquerda, de cartaz fixado em farmácia.

Figura 1 Cartazes. Elaborado pelos autores.
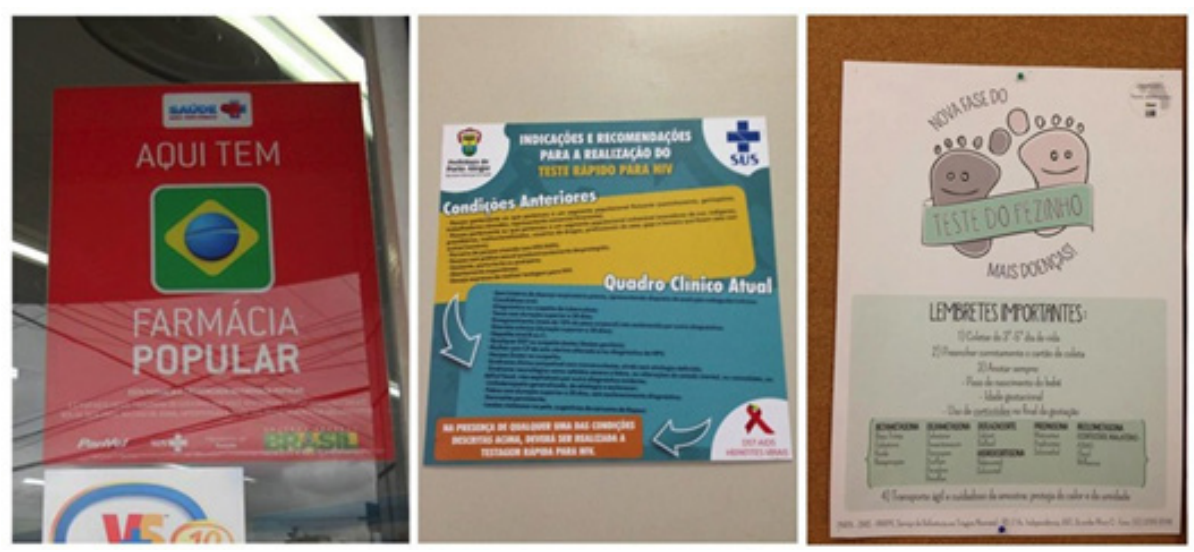

Nos materiais relacionados à saúde da mulher, constatamos algumas características como: utilização de personagens femininas, a cor rosa em predominância sobre outras cores, exploração de signos que fazem analogia a feminilidade, como, flores, esmaltes, coração e ainda, a presença de figuras públicas, como mostrado no topo da Figura 2, onde está uma das cantoras brasileiras mais populares, Claudia Leitte. Nesse sentido, Frascara (2006b) destaca que a estratégia de utilizar artistas famosos tende a produzir um ruído no material, pois a figura do artista, seu trabalho, acabam por se sobressair ao principal, que é o conteúdo comunicado, que pode acabar passando por despercebido por quem olha. Em relação as 
virtudes tratadas por Bonsiepe (2011), parte deles demonstrou leveza, porém, alguns como o que está à direita da Figura 2, possui excesso de textos, que dificultam a legibilidade. Sobre a última virtude, de visualidade, a maior parte possuía imagens fazendo relação, seja de forma análoga, com o que se estava informando verbalmente.

Figura 2 Cartaz e cartilha sobre saúde da mulher. Elaborado pelos autores.
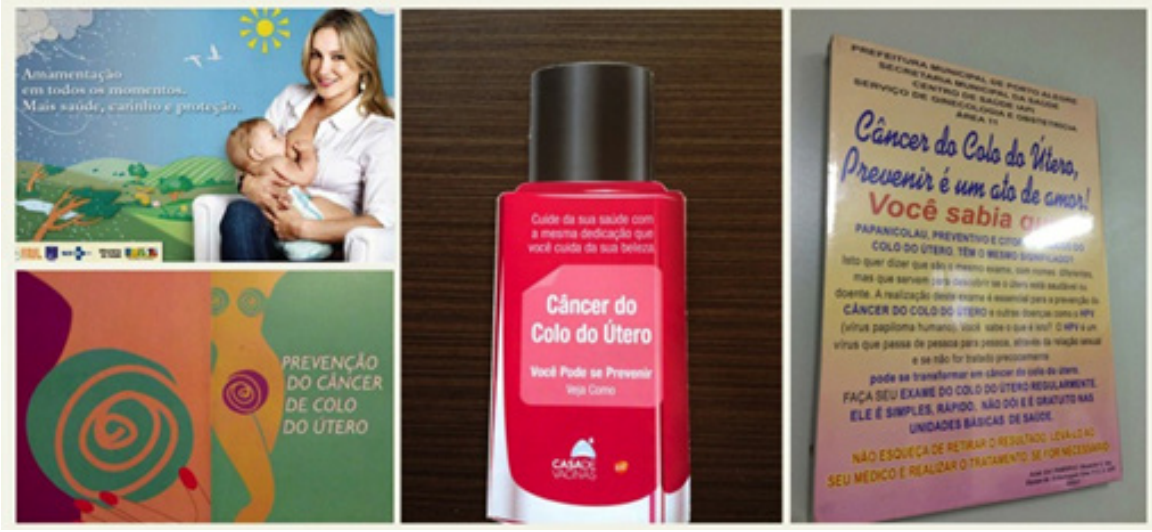

Na busca por inspiração em outros contextos, pesquisou-se estratégias de comunicação disponíveis em sites ${ }^{1}$ de referências de materiais de design. Dentre elas, as que pareciam mais pertinentes, por gerar curiosidade do público e maior identificação, pela linguagem, foi o origami, que está no topo esquerdo da Figura 3 e os cartazes com depoimentos de mulheres sobre beleza e saúde (inferior, à direita). No modelo de origami há perguntas na parte interna da dobradura e suas respostas encontram-se ao desdobrar as abas. A forma de comunicação deste modelo é viável, pois, demanda quantidade semelhante de papel de uma cartilha comum, e no entanto, maior manipulação para fazer as dobras do papel.

Figura 3 Referências de estratégias de comunicação. Elaborado pelos autores.

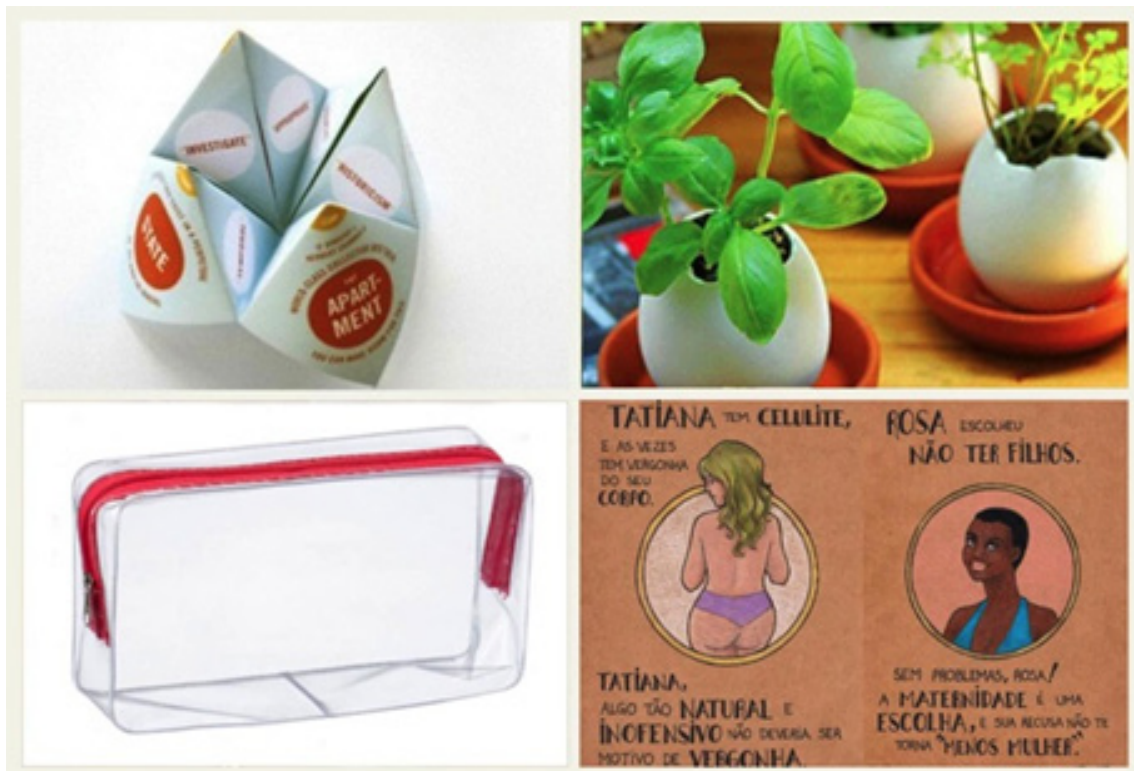


Ainda na fase Ouvir, partiu-se para entrevistas com pacientes da unidade do IAPI. Constatamos que elas já possuíam o hábito de se prevenir em relação ao câncer de colo de útero, conheciam pessoas próximas que tem medo de fazer o exame preventivo e já tentaram convencê-las a realizá-lo. Outro fator levantado nas entrevistas foi de que as mulheres, em geral, só procuram auxilio médico quando estão com sintomas de doenças. A partir destes relatos, identificamos a necessidade de estimular as mulheres que não vão aos centros de saúde, a procurar esses espaços para realizar a prevenção do câncer de colo de útero. Assim, chegou-se a diretrizes sobre a estratégia de comunicação, que deve ser voltada principalmente para as mulheres que não frequentam o centro de saúde. Contemplando nelas as virtudes apontadas por Bonsiepe (2011) para um design humanista:

- leveza na forma como as informações e imagens são alocadas no material, ter formato criativo e elegante, diferente de cartazes e cartilhas;

- $\quad$ intelectualidade, de postura crítica, que obtenha um papel relevante na sociedade;

- preocupando-se com esfera pública, adotar formas de levar as informações às pessoas, disponibilizando o material em locais estratégicos, locais frequentados pelas mulheres, como ônibus, salões de beleza, escolas, supermercados;

- alteridade concerne a disposição de respeitar outras culturas projetuais com seus valores inerentes;

- $\quad$ vinculado a visualidade, explorar o uso de ilustrações de personagens femininas contemplando os perfis e características estéticas das pacientes; utilizar linguagem verbal mais impessoal, de fácil compreensão; expor os textos a partir da lógica pergunta/resposta ou desafio/solução; explorar a curiosidade das pessoas, de forma que o material seja interativo.

Fase 2 - Criar

A etapa de criação ocorreu entre os meses de julho e setembro de 2014. A partir das diretrizes traçadas na primeira etapa e de uma analogia com o exame preventivo de câncer de colo de útero, criamos um formato no qual a informação não fosse externamente visível, que tivesse um estímulo para que elas buscassem a informação. Criou-se um primeiro esboço com o conceito: "bonita por fora e por dentro sempre: abra e descubra como". O conceito conota que não basta cuidar da aparência externa, mas também da interna, da saúde. Como símbolo para representar a beleza e trazer atributos de descoberta do que está escondido, escolheu-se uma flor. Utilizamos a técnica de origami para criá-la, como no exemplo da Figura 3. Na Figura 4 é mostrado o protótipo, que possui quatro perguntas na parte interna: (1) O que é o câncer de colo de útero?; (2) O que é o HPV?; (3) Como diagnosticar o câncer de colo de útero e (4) Como é o tratamento do câncer de colo de útero? Desdobrando cada uma das abas, 
encontram-se as respostas de cada uma destas questões, em textos diretos e uma ilustração ao centro. A ilustração do centro mostra uma personagem, contando sua experiência diante do câncer de colo de útero, partindo do autoexame, a relação com seus familiares, o diagnóstico e o sucesso do tratamento realizado.

Figura 4 Protótipo flor perguntas e respostas. Elaborado pelos autores.
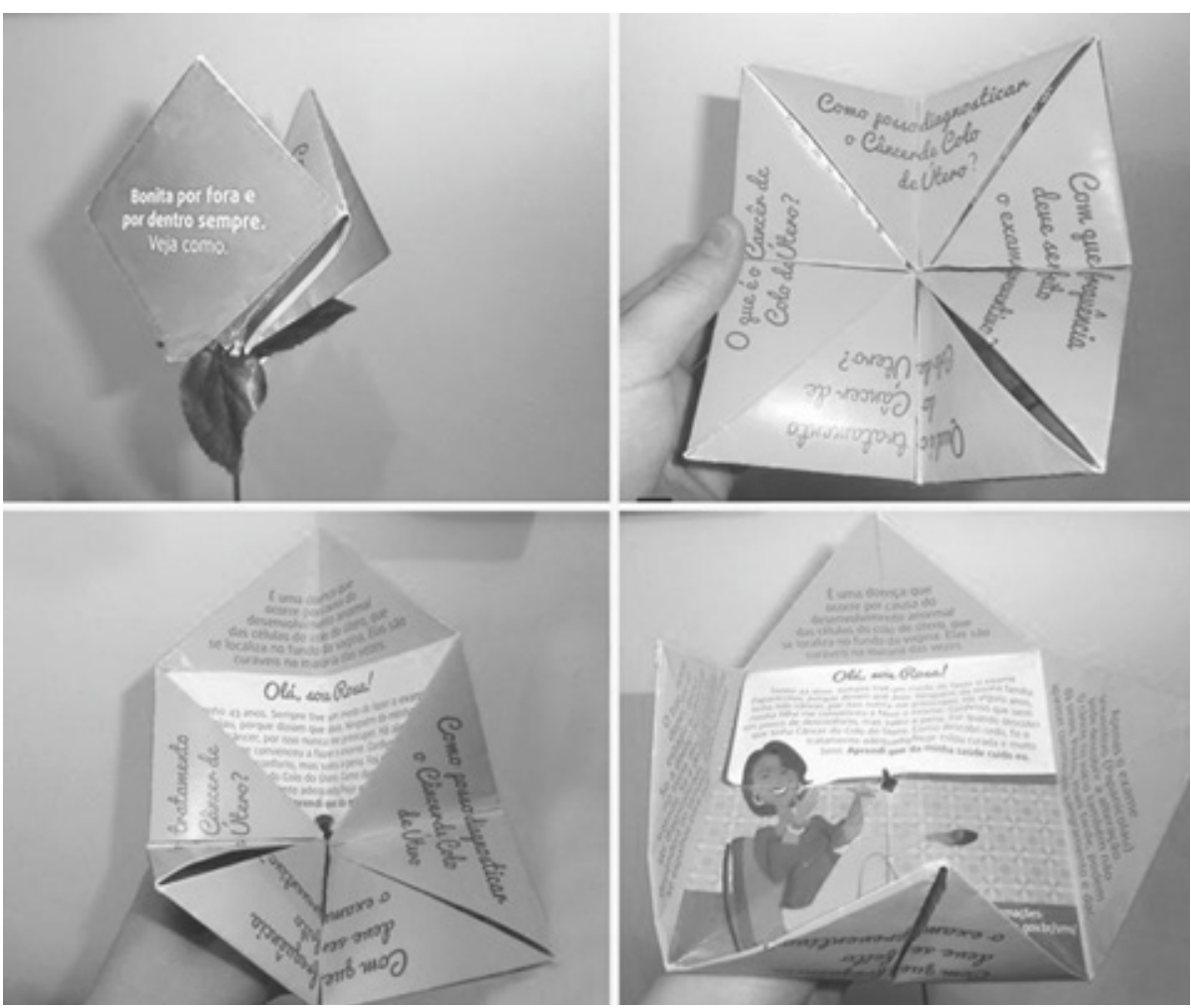

O protótipo foi inicialmente testado com o grupo de pesquisadores que não participaram da criação. Neste teste, foi notado que a flor tinha um tamanho muito grande e que a ilustração com história contida no centro da flor acabava por confundir a leitura das respostas, pois não ficava claro: (1) o que ler primeiro a história ou as perguntas, (2) se havia uma relação entre as perguntas e as respostas e a história da personagem. Para solucionar os problemas, pensamos que ao invés de dispor a história da personagem no centro da flor, colocá-la atrás de cada uma das abas de pergunta, de forma que cada depoimento respondesse à uma das quatro perguntas, assim, ilustramos outras três personagens. Além de tornar a leitura mais clara, a estratégia consistiu em trazer personagens com diferentes perfis e idades. Como as personagens respondem as perguntas através de seus depoimentos, utilizou-se uma linguagem não tão impessoal como no primeiro protótipo. Na Figura 5, está a segunda flor prototipada. 
Freire K. M. \& Oliveira C. M. M. | A criação de estratégia de comunicação para prevenção em saúde através do

Figura 5 Protótipo da flor com narrativas. Elaborado pelos autores.
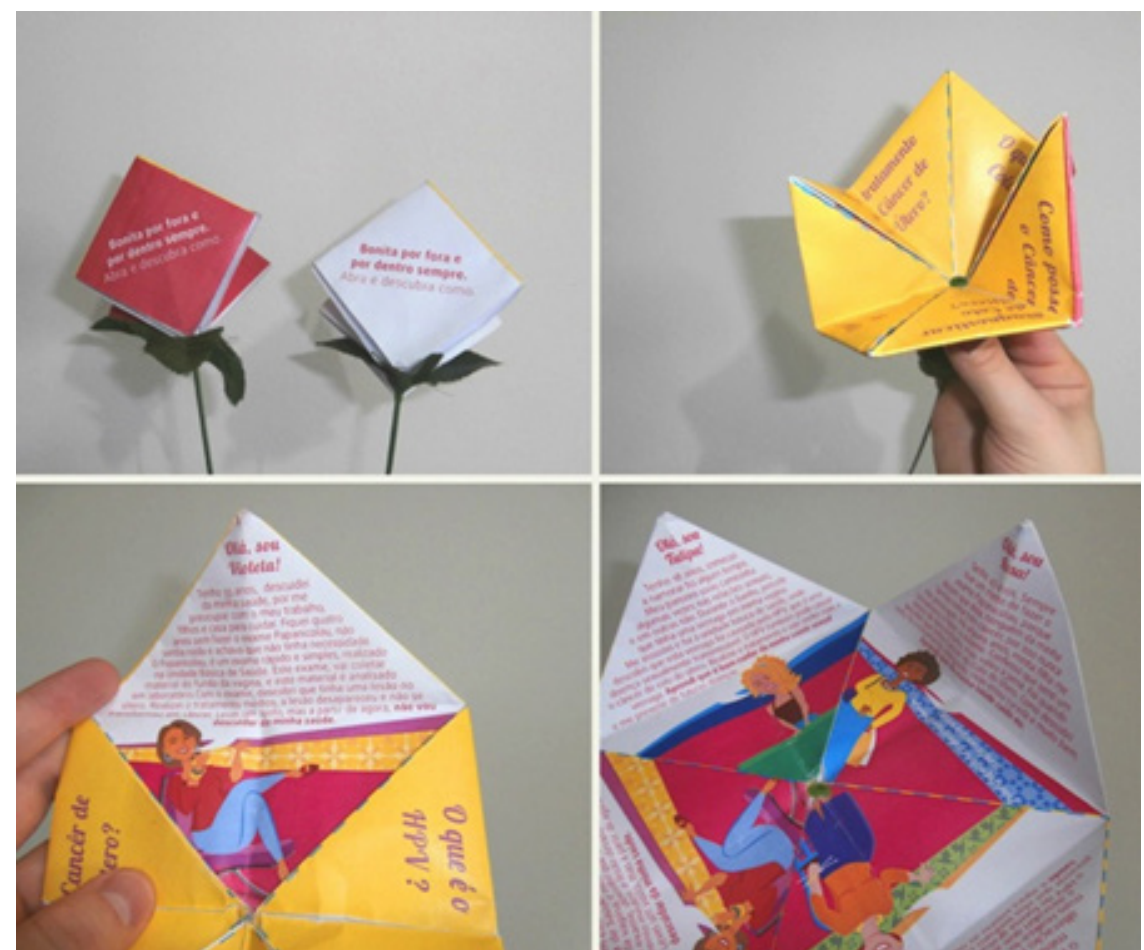

Fase 3 - Disseminar

Para avaliar a pertinência da segunda flor, foram realizados: (1) entrevistas diretas com mulheres da comunidade e (2) uma pesquisa de comparação entre um modelo tradicional de cartilha e o da flor. Para isso, foi criado um folder (Figura 6), com o mesmo conteúdo presente na flor, e levados a salões de beleza do IAPI. A estratégia era observar a reação das mulheres ao encontrar ambos os formatos dispostos sobre uma mesa (Figura 7) e verificar qual deles era mais eficiente. Esta segunda pesquisa foi de observação em um primeiro momento e de entrevistas em profundidade após elas pegarem para ler os materiais.

Figura 6 Protótipo do folder em formato padrão com narrativas. Elaborado pelos autores.

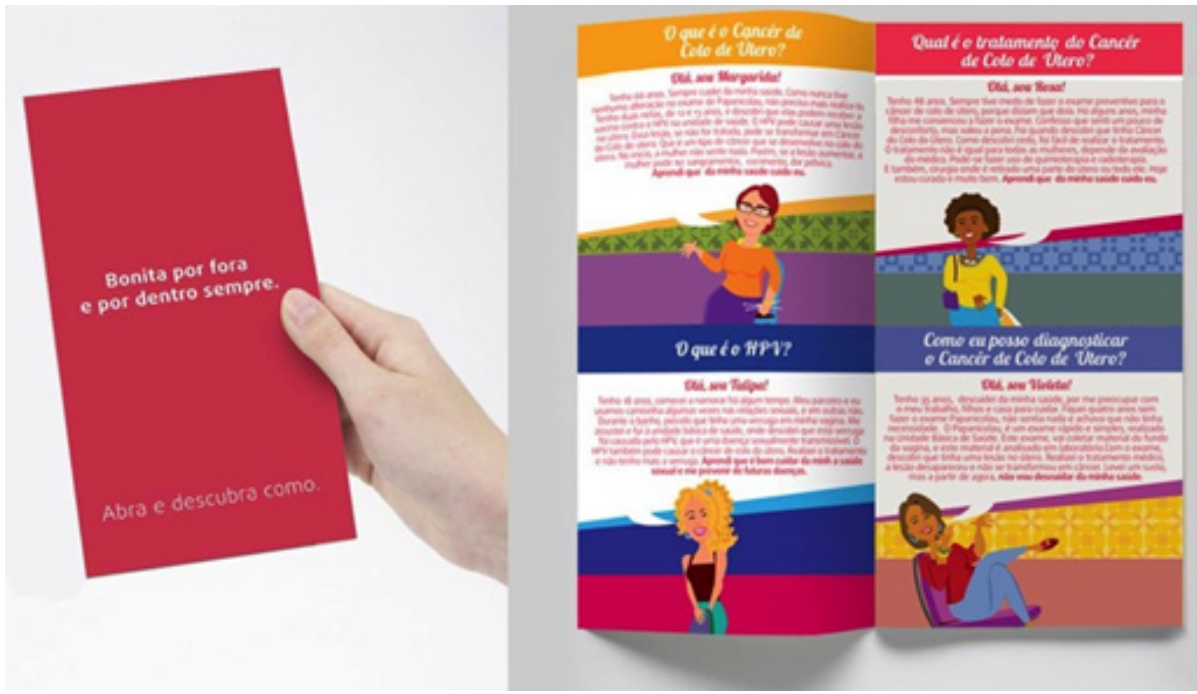


Nas entrevistas diretas, levamos as flores coloridas (com as pétalas rosas ou roxas ou brancas) e flores completamente em preto e branco. No primeiro momento as entrevistadas recebiam a flor em preto e branco, e nesta intervenção percebemos que:

- a maior parte das mulheres conseguia perceber que o material representava uma flor;

- elas demonstraram curiosidade ao ver a flor, porém parte delas hesitou em abri-la, demonstrando receio em estragá-la;

- quando solicitamos que elas escolhessem uma cor para as pétalas da flor, a maior parte sugeria a cor rosa, pois representava mais a feminilidade e relação com a campanha "Outubro Rosa", que utiliza a cor rosa para simbolizar a luta contra o câncer de mama. Após as respostas, mostramos à elas as flores coloridas, com pétalas rosas, roxas e brancas;

- $\quad$ em relação aos textos, parte delas achou que as respostas eram extensas e como algumas estavam sem seus óculos, tiveram dificuldades para ler;

- $\quad$ sobre o conceito da flor e a utilização de personagens femininas contando suas histórias, elas disseram terem gostado e que eram ideias criativas.

Após este primeiro momento, fizemos ajustes no protótipo, como aumento das fontes tipográficas e redução dos textos. Assim, foi realizado um segundo momento de testes, em salões de beleza (Figura 7). Realizamos sete entrevistas, com mulheres de diferentes idades: quinze anos (1 pessoa), entre vinte e vinte e cinco anos (3 pessoas), entre trinta e quarenta anos ( 2 pessoas) com mais de cinquenta (1 pessoa). Seis delas já conheciam informações sobre o câncer de colo de útero e apenas uma, a mais nova, não conhecia a doença. Em SUS, cinco delas afirmaram já terem utilizado, e destas, duas já frequentaram o Centro de Saúde IAPI.

Figura 7 Flores e cartilhas em salão de beleza do bairro IAPI.

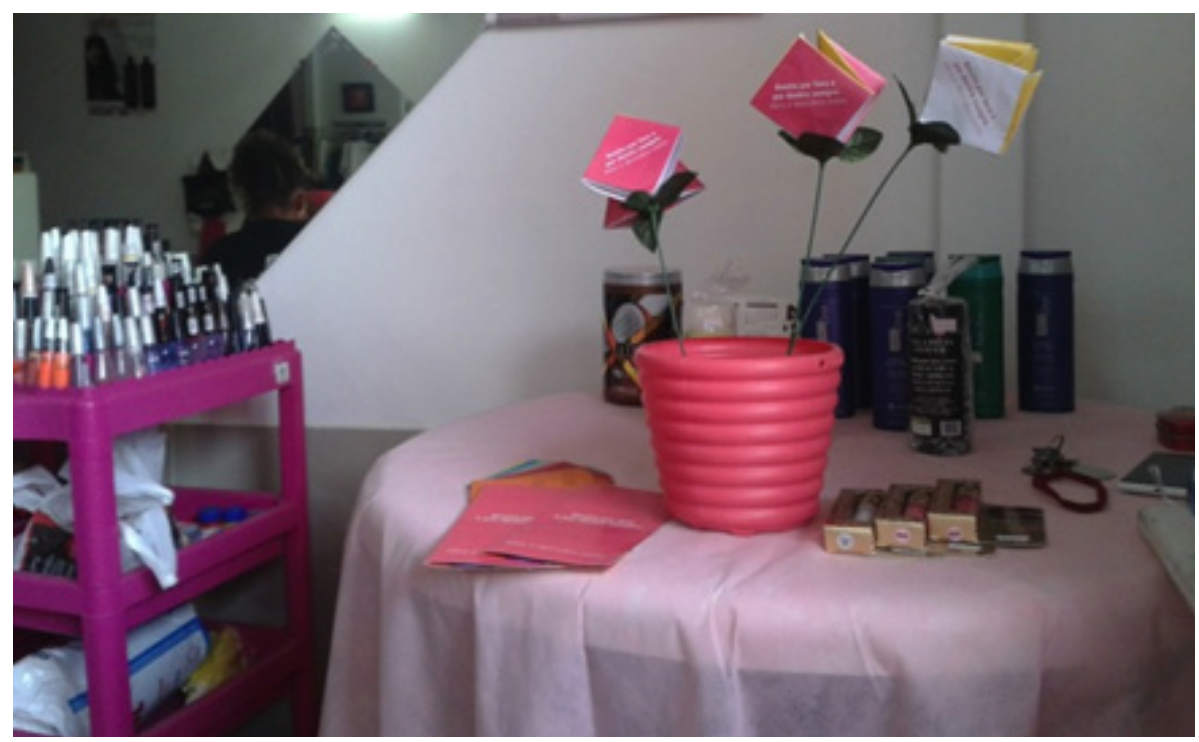


As respostas das entrevistadas foram analisadas a partir de quatro categorias analíticas, demonstradas na Figura 8. Considerando a atratividade da flor, as entrevistadas afirmaram que o material se se destaca no local que é disposto, por suas cores vibrantes e formato inusitado. A estratégia também foi apontada por representar algo de especial, que fizesse com que as mulheres queiram pegar o material, guardar e mostrar para as amigas e familiares. Porém, duas entrevistadas sugeriram que a abordagem do material fosse mais impactante, salientando mais os perigos da doença, que pode levar a complicações à saúde e à morte, se não tratada com os devidos cuidados.

Em relação à funcionalidade, foram levantados atributos envolvendo a legibilidade, o manuseio e a compreensão. De legibilidade, duas delas disseram preferir ler a cartilha comum, pois os textos da flor, embora com o mesmo tamanho de letra, possui menor entrelinha, devido ao espaço limitado de cada aba e quantidade de dobras. Uma destas duas achou um pouco cansativo a leitura, pois disse que eram muitas informações. As outras cinco mulheres disseram ser tranquilo e fácil de ler. Quanto ao manuseio, duas delas apresentaram certa dificuldade em abrir a flor, em descobrir por onde começar a ler, e uma destacou a preferência por ler a cartilha pois não precisava desdobrar várias abas, mas ainda assim, como estratégia, gostou mais da flor. Considerando aspectos de compreensão, todas afirmaram ser de fácil assimilação e que a ideia de explorar personagens contando suas histórias era interessante, em comparação as cartilhas mais comuns. Em relação a identificação com as personagens ou com as histórias, apenas uma se identificou com uma das personagens e outras duas disseram lembrar de histórias de conhecidas que tiveram a doença. Na avaliação sobre percepção para motivação, embora não tenha como avaliar se realmente haverá mudança de comportamento pois depende de diversos fatores pessoais, pôde-se apenas ouvir das entrevistadas se elas acreditavam que a estratégia da flor as incentivava (ou suas amigas e familiares) a realizarem o exame preventivo e de autocuidado. Uma das entrevistadas disse que além de entregar a flor, para estimular amigas a fazer o exame, era necessário conversar com elas sobre o assunto, que apenas a flor sozinha não faria tanto efeito para mudar comportamentos. 
Figura 8 Falas mais significativas.

\section{ATRATIVIDADE \\ "esse aqui (flor) parece mais elaborado, parece que a pessoa é mais selecionada [...] algo mais especial" (ENTREVISTADA A) \\ "é uma coisa que eu guardaria [...] todas pegariam, da forma que vocess estáo apresentando, ela chama bastante atençáo (ENTREVISTADA B) \\ "gostei mais da flor, achei bem legal, bem colorido [...] gostei das ilustraçóes, achei bem bonitinho os personagens [...] eu levaria para uma amiga minha" (ENTREVISTADA D) \\ "eu gostei mais da rosa, [...] justamente porque é diferente, o design é diferente, tudo e mais chamativo" (ENTREVISTADA G) \\ 3. IDENTIFICAÇÃO CULTURAL \\ "náo, náo me identifiquei com ninguém" (ENTREVISTADA A) \\ "sim, com a de dezoito anos, por causa da idade" (ENTREVISTADA F) \\ "eu pessoalmente, eu náo me identifiquei, mas eu tenho o caso de uma parente minha que aconteceu de ela ter descoberto uma feridinha no útero, mas ela se tratou logo em seguida e náo chegou a virar tumor" (ENTREVISTADA G) \\ 2. FUNCIONALIDADE \\ "achei um pouco cansativo (sobre quantidade de texto) [...] acredito que tenha que ser alguma coisa com bem mais impacto" (ENTREVISTADA A) "achei perfeito, tranquilo" (ENTREVISTADAC) "eu gostei da quantidade de informaçóes, do tamanho, so que esse aqui (cartilha comum) fica mais fácil de ler, náo precisa ficar desdobrando...mas entregaria a flor" (ENTREVSTADAE) \\ "adorei os desenhos, eu adorei as historias. Porque eu acho que com uma historinha é mais fácil para tu assimilar, náo importa o teu nivel social": (ENTREVISTADA G) \\ 4. PERCEPÇĀO PARA MUDANÇA DE COMPORTAMENTO \\ "acho que sim" (se ela entregasse a flor a amigas, se elas fariam o exame) (ENTREVSTADA D) \\ "sim, iriam" (ENTREVISTADAE) \\ "fariam, a gente pode dar uma forcinha, mas claro que depende de cada um, depende da consciencia de cada um" (ENTREVISTADA G)}

Como resultados desta pesquisa, verificamos a pertinência do processo de design centrado no ser humano para desenvolver mais que materiais de comunicação, mas estratégias compreensíveis, atraentes, focadas na percepção, cultura e necessidades dos usuários. O processo trouxe elementos fundamentais para a definição da estratégia de comunicação: distribuição fora dos espaços de saúde do SUS, linguagem informal baseada em histórias e ilustrações e formato inusitado para estimular as usuárias a pegá-lo. Os resultados desta pesquisa exploratória indicam que o material seria notado no conjunto de informações que uma mulher recebe ao longo do dia e a estratégia de utilizar espaços no qual as mulheres frequentam, como salões de beleza é adequado. Nesses lugares, elas inclusive discutem os temas abordados no material. Há indicativos que esse tipo de estratégia de comunicação pode incentivar a mudança de comportamento e promover atitudes de autocuidado. 


\section{Considerações finais}

A partir desta pesquisa apresentamos a pertinência do processo de design centrado no ser humano para estratégias de comunicação voltadas ao autocuidado. Ao considerar a participação dos usuários no processo, é possível entender como os artefatos criados serão compreendidos e se serão desejados por estes. Com essa abordagem, consideramos não apenas o produto gráfico, mas como uma estratégia de comunicação, que se preocupa com a forma como os artefatos serão experimentados em seus contextos de uso.

A etapa ouvir, que incorpora a perspectiva dos usuários nos contextos de uso foi importante para que a equipe de design conseguisse compreender o mundo pelos olhos das pessoas que iriam usar os materiais educativos. Foi possível perceber a abundância de informações disponíveis a elas e a pouca atratividade do material existente. Na etapa criar, a equipe definiu de um formato inusitado (flor em comparação ao modelo comum de folder) para o material educativo e por meio de protótipos as usuárias participaram da escolha dos formatos, tipografia e cores. A flor mostrou-se mais eficaz, pois conseguiu comunicar os conteúdos relativos ao câncer de colo de útero de forma criativa, atrativa, estimulante e compreensível. Em relação a escolha dos locais de distribuição do material a estratégia de comunicação de campanhas que promovam o autocuidado mostrou-se adequada a escolha de salões de beleza, pois nesses espaços as mulheres já estão cuidando de si e dialogando com outras mulheres sobre esses cuidados.

Portanto, a partir desta pesquisa identificamos a pertinência do processo de design centrado no ser humano para projetar estratégias de comunicação considerando tanto os sistemas culturais da comunidade, quanto o conhecimento de percepção visual e psicologia da aprendizagem, de forma que as relações estabelecidas com a comunidade sejam compreensíveis, convergentes a conscientização sobre comportamento preventivo.

\section{Agradecimento}

Agradecemos aos pesquisadores do GEAPSA - Grupo de Estudos Avançados em Psicologia da Saúde da Unisinos que integraram essa pesquisa.

\section{Referências}

BONSIEPE, Gui. 2011. Design, Cultura e Sociedade. São Paulo: Blucher. FRASCARA, J. 1997. Diseño gráfico para la gente. Buenos Aires: Infinito. FRASCARA, Jorge (Ed.) 2006a. Design for Effective Communications: Creating Contexts for Clarity and Meaning. Allworth Press, New York, New York. 
FRASCARA, Jorge. 2006b. El diseño de comunicación. Buenos Aires: Infinito. IDEO. 2009. The Human centred design toolkit. 2nd edition.

IDEO. 2015. Website. Disponível em: https://www.ideo.com/work/humancentered-design-toolkit/ . acesso em outubro de 2015.

ISO, 2010. ISO 9241-210: Ergonomics of human-system interaction - Part 210: Human-centred design for interactive systems.

SBORDONE, M. A. 2008. Human-Centred Design: sustainable ideas and scenarios for the development of projects and products based on knowledge and human abilities. Revista Internacional de Sostenibilidad, Tecnología y Humanismo, 127-157.

STEEN, M. 2008. The fragility of human-centred design. Delft University, Amsterdam.

THIOLLENT, Michel. 1996. Metodologia da pesquisa-ação. $7^{\text {a }}$ ed. São Paulo: Cortez.

\section{Sobre os autores}

\section{Karine de Mello Freire}

Doutora em Design pela Pontifícia Universidade Católica do Rio de Janeiro - PUC-Rio. É professora do PPG Design da Unisinos e seu foco de pesquisa é o Design Estratégico para a Inovação Social, tendo por objeto de estudo o design voltado a serviços de saúde.

<kmfreire@unisinos.br>

\section{Caio Marcelo Miolo de Oliveira}

Mestrando em Design pela Universidade do Vale do Rio dos Sinos. Seu foco de pesquisa é o Design para a Inovação Social tendo por objeto de estudo os processos projetuais para o desenvolvimento de soluções habilitantes.

<caiomarcelo.mo@gmail.com>

Artigo recebido em 21 abr. 2015, aprovado em 23 nov. 2015. 